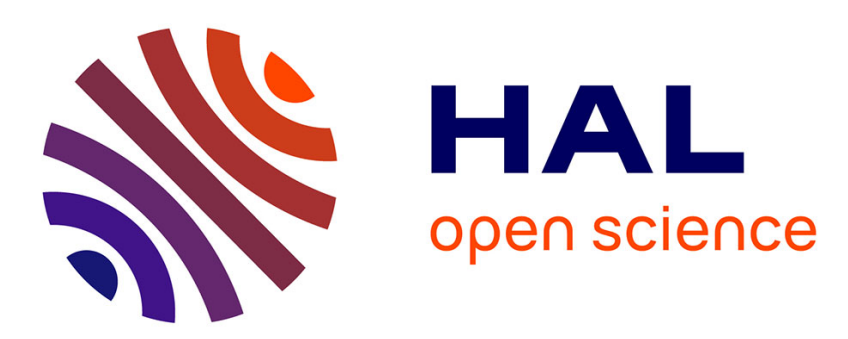

\title{
Physical properties of epoxy and free volume evaluated by positron annihilation spectroscopy
}

\author{
T. Okada, S. Nishijima, Y. Honda, Y. Kobayashi
}

\section{To cite this version:}

T. Okada, S. Nishijima, Y. Honda, Y. Kobayashi. Physical properties of epoxy and free volume evaluated by positron annihilation spectroscopy. Journal de Physique IV Proceedings, 1993, 03 (C4), pp.C4-291-C4-294. 10.1051/jp4:1993447 . jpa-00251490

\section{HAL Id: jpa-00251490 https://hal.science/jpa-00251490}

Submitted on 1 Jan 1993

HAL is a multi-disciplinary open access archive for the deposit and dissemination of scientific research documents, whether they are published or not. The documents may come from teaching and research institutions in France or abroad, or from public or private research centers.
L'archive ouverte pluridisciplinaire HAL, est destinée au dépôt et à la diffusion de documents scientifiques de niveau recherche, publiés ou non, émanant des établissements d'enseignement et de recherche français ou étrangers, des laboratoires publics ou privés. 


\title{
Physical properties of epoxy and free volume evaluated by positron annihilation spectroscopy
}

\author{
T. OKADA, S. NISHIJIMA, Y. HONDA and Y. KOBAYASHI* \\ Institute of Scientific and Industrial Research, Osaka University, Japan \\ * National Institute of Materials and Chemical Research, Tsukuba, Ibaraki, Japan
}

\begin{abstract}
The macroscopic physical properties of commercially available bisphenol -A epoxy resins cured by acid anhydride in which amount of the plasticizer, polypropyleneglycol was changed systematically have been measured and were compared with the amount of free volume evaluated by the positron annihilation technique. The lifetime and the intensity of orthopositronium were used to evaluate the amount of the free volume in the epoxy resins. It was found that up to the certain amount of plasticizer, the amount of the free volume did not increase so much and then showed the marked increase. The close correlations were found between the amount of the free volume and the macroscopic physical properties such as hardness and specific volume.
\end{abstract}

\section{Introduction}

Positron annihilation spectroscopy (PAS) is thought to be promising method to evaluate the free volume or microvacancies 1,2 which control the physical characteristics of organic materials. The life time, $\tau_{3}$ and the intensity, $I_{3}$ of the long-lived component in polymers are considered to be the contribution from the orthopositronium (o-Ps) which has close relationship between size and concentration of free volume. 3-5 PAS could be therefore, can be applied to the molecular design giving the desirable properties to the glassy polymers. The correlation between the free volume evaluated in terms of PAS method and the macroscopic physical properties should be understood in practical application of PAS to the molecular design of glassy polymers. In this work the epoxy resins were chosen and the evaluated free volume by means of PAS were compared with the physical properties.

\section{Experimental}

The commercially available epoxy resin bisphenol-A of which molecular weight was approximately 397 was chosen. The acid anhydride as a hardener, tertiary amine as an accelerator and polypropyleneglycol (molecular weight 373 ) as a plasticizer were used. The amount of plasticizer was changed systematically and was presented in Table 1 . The curing condition was $353 \mathrm{~K}$ for 4 hours and $423 \mathrm{~K}$ for 5 hours.

The Vickers hardness, Young's modulus and flexural strength were measured as mechanical properties. The Young's modulus and flexural strength were calculated from the results of 3 point bending tests. The bending speed was set at $2 \mathrm{~mm} / \mathrm{min}$. Vickers hardness was measured at $50 \mathrm{gf}$ load. The density was measured in terms of hydrometer. The glass transition temperature and the thermal expansion coefficients were measured by thermal mechanical analysis system at the temperature increasing rate of $5 \mathrm{~K} / \mathrm{min}$. The positron lifetime measurement was performed by means of fast-fast coincidence system. The resolution time of the system was $400 \mathrm{psec}$ (FWHM). All the measurements were performed at room temperature (approximately $293 \mathrm{~K}$ ). 
Table 1 Formulation of blends and their glass translation temperature

\begin{tabular}{crrrrr}
\hline Sample No. & 1 & 2 & 3 & 4 & 5 \\
Blend ratio in weight & 100 & 100 & 100 & 100 & 100 \\
Epoxy & 100 & 100 & 100 & 100 & 100 \\
Hardener & 1 & 1 & 1 & 1 & 1 \\
Accelerator & 0 & 15 & 30 & 45 & 60 \\
Plasticizer & 0 & 7 & 13 & 18 & 23 \\
Plasticizer (wt\%) & 365.3 & 341.1 & 317.7 & 303.2 & 291.7 \\
Glass transition temperature $(K)$ & & & & &
\end{tabular}

\section{Results}

In Table 1 the glass transition temperatures of each materials were also shown. The glass transition temperature decreased with increasing the amount of the plasticizer. In Fig.1 the changes of Vickers hardness and Young's modulus were shown. As the amount of plasticizer increased, Vickers hardness and Young's modulus decreased. Especially at more than $13 \%$ of plasticizer, the decrement of each properties came to be marked. The flexural strength and density decreased in the same manner.

In Fig. 2 the changes of life time of $\mathrm{o}-\mathrm{Ps}, \tau_{3}$ and intensity $\mathrm{I}_{3}$ with amount of plasticizer were

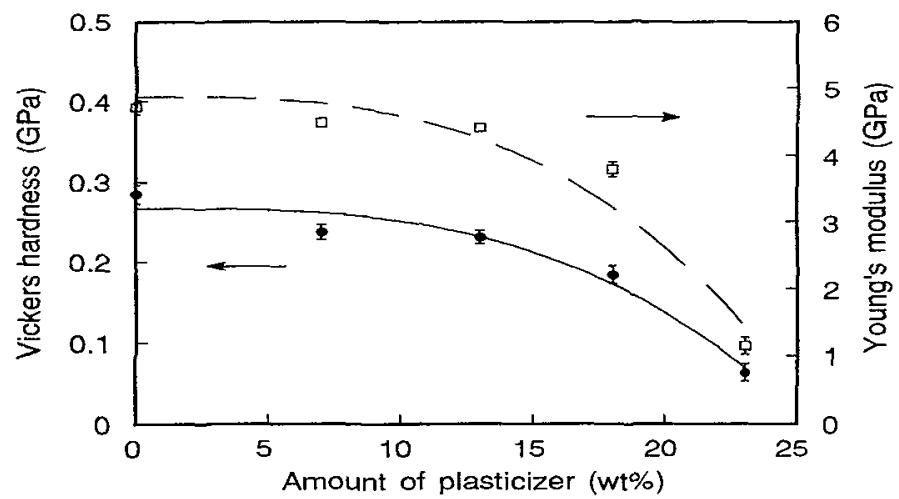

Fig. 1 Amount of plasticizer dependence of Vickers hardness and density.

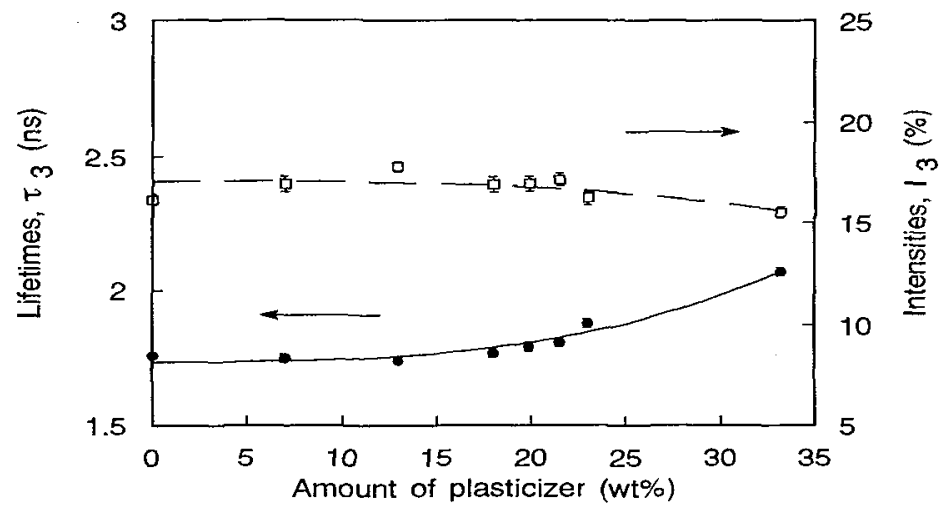

Fig. 2 Amount of plasticizer dependence of $\tau_{3}$ and $\mathrm{I}_{3}$. 


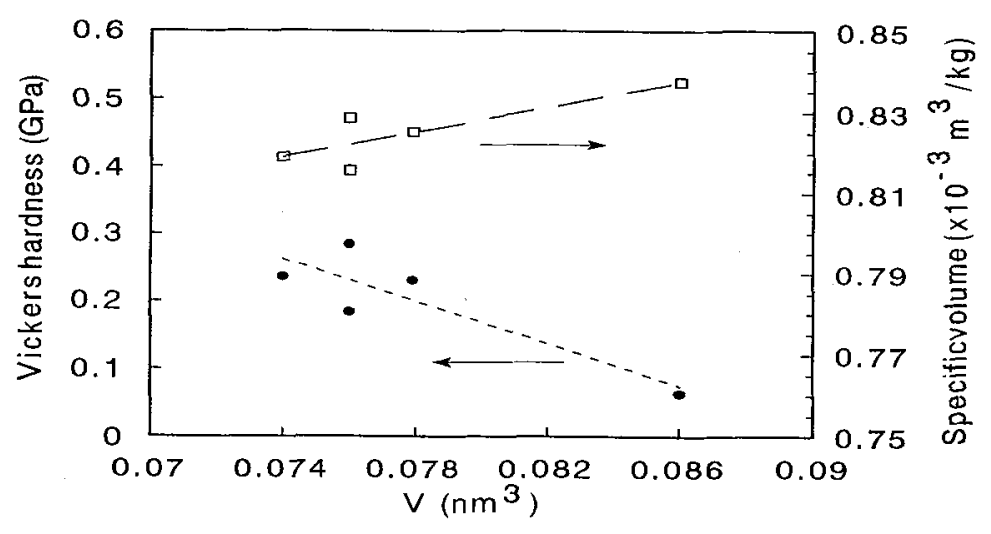

Fig. $3 \mathrm{~V}$ dependence of Vickers hardness and specific volume.

presented. The $\tau_{3}$ increased with the amount of plasticizer. It was reported that as the amount of the acid anhydride of which electron affinity was strong increased, the formation of o-Ps was suppressed due to the chemical quenching results in decrease of $\mathrm{I}_{3}{ }^{6}$ In this experiment as the amount of the acid anhydride hardener decreased, that is the amount of plasticizer increased, I3 decreased and hence the change was not brought by the acid anhydride.

\section{Discussion}

The long lived life time $\tau_{3}$ is thought to be related to the size of the free volume. ${ }^{7,8}$ The volume $\mathrm{V}$ corresponds to $\tau_{3}$ was calculated where the free volume was supposed to be sphere. The calculated $V$ and the product $\mathrm{V}$ and $\mathrm{I}_{3}$ were thought to be the representatives of free volume. In Fig. 3 the correlation between $\mathrm{V}$ and hardness or specific volume were presented and in Fig. $4 \mathrm{VxI}_{3}$ and hardness or specific volume. It was seen that the strong correlation between the macroscopic properties and $\mathrm{V}$ or $\mathrm{VxI}_{3}$. Both properties are

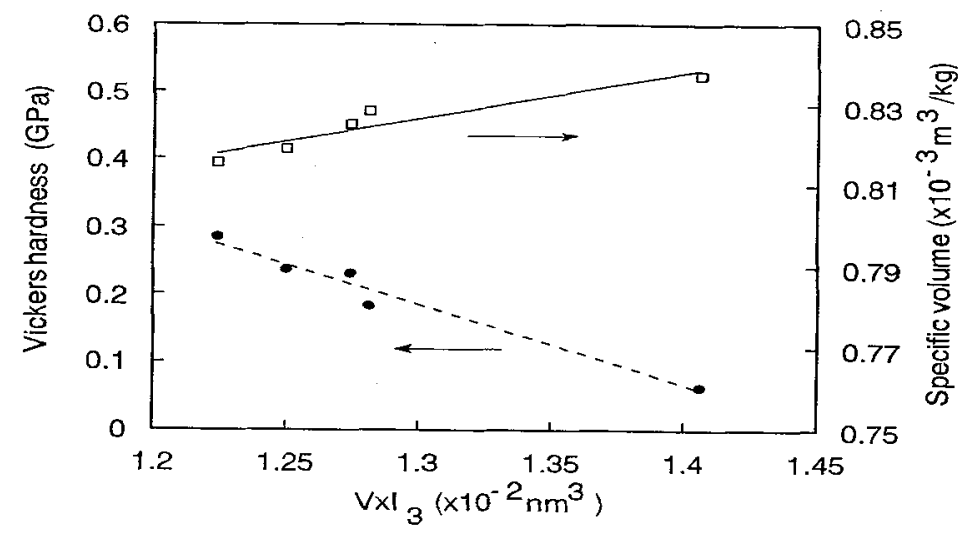

Fig. 4 VxI3 dependence of Vickers hardness and specific volume. 
thought to have closed correlation to the free volume. Hardness should depend on the amount of free volume, because the increase of free volume brings the increase of possible volume for plastic deformation results in the decrease of hardness. The specific volume can be thought to be the sum of free volume and occupied volume by molecules and hence the specific volume decreases with increasing free volume. Within this experiment, the strong correlation was found between them. It means that the free volume control the macroscopic physical properties of glassy polymer. In glassy polymer the amount of free volume is thought to be constant of $2.5 \%$. Though the epoxies in this work were thought to be in the glassy state as shown in Table 1, the total amount of free volume evaluated by PAS method were varied. This is because that the off set of the glass transition might be below $293 \mathrm{~K}$ or the free volume could change even in glassy state.

The macroscopic physical properties are decreased markedly by the plasticizer higher than $13 \%$. This phenomenon is due to the introduction of free volume by the plasticizer judging from present data. When the plasticizer added excessively, the new phase appears which is mostly plasticizer. The phase contributes to the increase of free volume because of the mobility of the plasticizer should be larger than that of networked epoxy.

\section{Conclusion}

The macroscopic characteristics of epoxy resins were compared with the $\mathrm{V}$ and $\mathrm{VxI}_{3}$ which are thought to be the representatives of the free volume evaluated by the PAS method changing the amount of plasticizer in the epoxy resins. It was found that the excessive plasticizer came to form the new phase and the plasticizer changed the physical properties of epoxy markedly such as decrease of hardness, Young's modulus, density and strength. The change can be explained by the increase of the free volume due to the plasticizer and the free volume could be evaluated by PAS method.

\section{Acknowledgment}

The authors are grateful to Dr. J. Ohkuma in Radiation Laboratory, ISIR Osaka Univ. for his help of handling the radioisotopes. This work is partly supported by the cooperative work "Advanced Materials Creation and Their Limit State Protection for Environmental Preservation" between Institute of Scientific and Industrial Research and Welding Research Institute in Osaka University.

\section{References}

1. Brandt, W., Berko, S. and Walker, W., W. Phys. Rev. 120 (1960) 1289

2. Stevens, J. R. and Mao, S., J. J. Appl. Phys. 41 (1970) 4273

3. Kobayashi, Y., Zheng, W., Meyer, E. F., McGervey, J. D., Jameison, A. M. and Simha, R. , Macromolecules 22 (1989) 2302

4. Kobayashi, Y., J. Chem. Soc. Faraday Trans. 87 (1991) 3641

5. Hinkley, J. A., Eftekhari, A, Crook, R. A., Jensen, B. J. and Singh, J. J., J. Polym. Sci., Part B: Polym. Phys. 30 (1992) 1195

6. Okamoto, K., Tanaka, K., Katsube, M., Sueoka, O. and Ito, Y., Radiat. Phys. Chem. 41 (1993) 497

7. Deng, Q., Sundar, C. S. and Jean, Y. C. , J. Phys. Chem. 96 (1992) 492

8. Y. C. Jean, 'Positron and Positronium Chemistry' (Ed. Y. C. Jean), World Scientific, London, (1990)1 